\title{
Biomechanical Characteristics of Metal Plate Fixators and Composite Plate Fixators
}

\author{
D. Bubesh kumar, P. Kumaran, David Barnabas, Akash J, Jagadeeswaran S
}

\begin{abstract}
Biomedical properties of Metal Plate fixators and Composite fixators were carries out. Fatigue of the metal and composite materials were carried out, Dynamic mechanical analysis, Shear strength and tensile strength of the composite materials were also carried out. Finite element analysis of the plate fixator was carried out it. The results shows metal fixators are rigid and their strength is more than the bone, whereas composite materials can be tailor made to the need. Delamination occurs in composite materials.
\end{abstract}

Keywords : FEA, Biomechanical, SIFC.

\section{INTRODUCTION}

Millions of people all over the world undergo surgery for fracture. Fracture plates are widely used fracture injuries of the tibial bone[1]. Biomechanical properties of metal plate and composite plate fixators are studied in this paper. This is useful in quick healing of the fracture[2]. In this biomechanical experiments fatigue test, Dynamic Mechanical analysis test, shear strength test, tensile strength test were carried out[3]. This biomechanical tests helps in improving the biomechanical properties of the metals and composites used in implants and the fixators [4]-[5].

\section{Methodology}

The methodology is testing of the surface impact fatique corrosion of biomedical implants and fixators is repeated loads on the composite and metal implants[6]-[7]. Finite Element Analysis of the fixator and implants are passed through utilizing finite element software ANSYS WorkBench 18 software package .

\section{RESULT AND DISCUSSION}

Modelling and Analysis of Plate fixators .

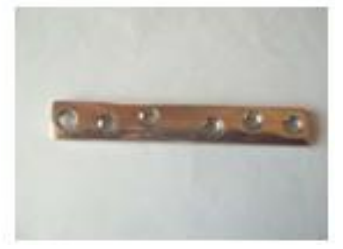

Revised Manuscript Received on December 16, 2019

* Correspondence Author

D. Bubesh kumar *, Associate Professor, Department of Mechanical Engineering, AVIT, Chennai, Tamil Nadu, India. Email: bubeshkumar@avit.ac.in

P.Kumaran, Asst. Prof, Department of Mechanical Engineering, AVIT, Chennai, Tamil Nadu, India.

David Barnabas, Akash J, Jagadeeswaran S, UG Scholar, Department of Mechanical Engineering, AVIT, Chennai, Tamil Nadu, India.
Fig. 1.316L Stainless Steel plate fixator.

The above figure 1 shows 316 Stainless Steel plate fixator, which is used in the fracture fixation of the tibial bone[8]. The figure 2 shows impact load on the plate fixator.

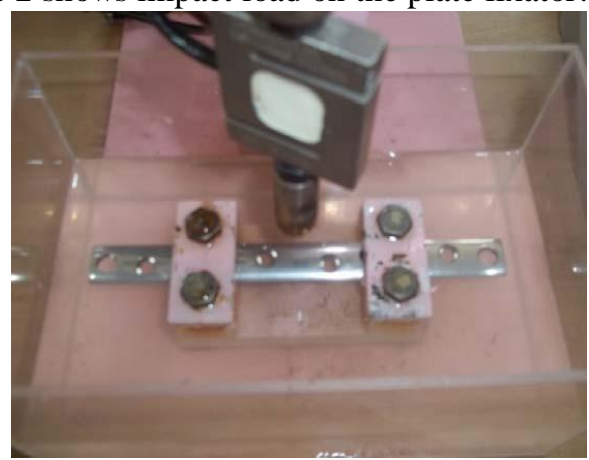

Fig. 2.Stainless steel plate fixator on SIFCM .

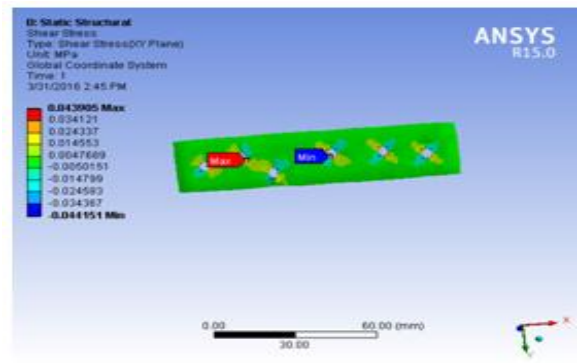

Fig. 3.Stainless Shear stress on 316L SS

The above figure 3 shows Shear stress on 316L SS with $1800 \mathrm{~N}$ load. Red mark on holes of the plates shows maximum shear stress has occurred on the plate.

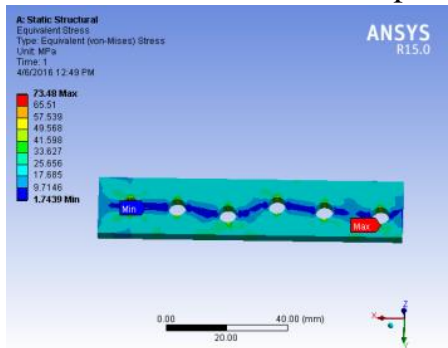

Fig. 4.Equivalent stress on $1800 \mathrm{~N}$ titanium grade 1

The above figure 4 shows Equivalent stress on $1800 \mathrm{~N}$ titanum grade 1 the highest stress occurs on side wall of the hole. FEA is carried out on Aluminum, Titanium and 316L SS plate fixators.1800N load is applied at the centre of the above fixators. From the FEA, it is found that the strains and stresses arises at middle line 
which connects the holes on the fixators [9]-[10]. The red line shows more stresses and strains occur at these parts of the fixator and shows various stresses on the fixator materials viz., Aluminium, Titanium, 316L SS.

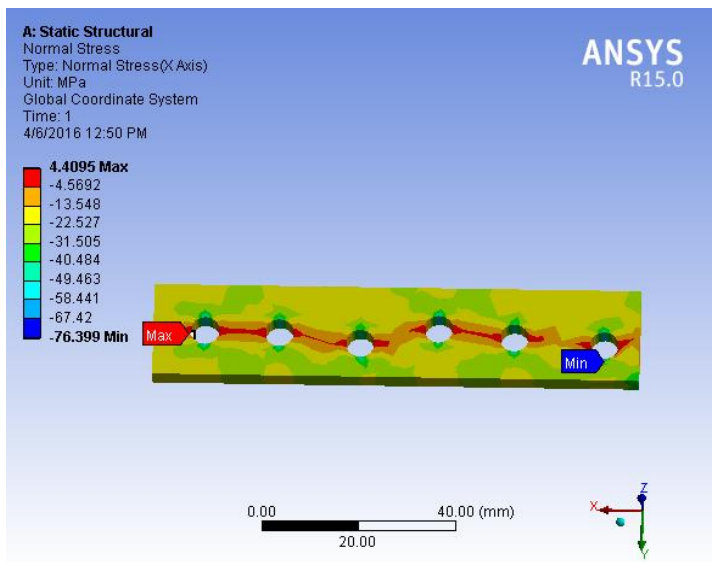

Fig. 5.FEA results of normal stress on Aluminium plate fixator.

The above Figure 5 shows FEA results of normal stress on Aluminium plate fixator. The red line shows normal stress, the maximum normal stress, extends from one end of the axis to the other end, and the maximum normal stress acts on the fixator.

\section{A. Carbon Epoxy Composite Material}

Carbon is widely used in implants and fixator for orthopaedic patients. Carbon implants fixators is light in weight. The researcher fabricated carbon epoxy fixators and tested its mechanical properties[11].

\section{B. Mechanical Test Carbon Epoxy Composite}

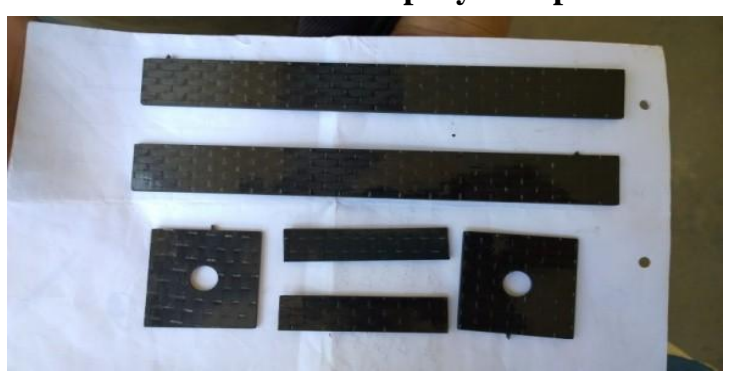

Fig. 6. Tensile Strength, Shear Strength, Dynamic Mechanical analysis samples.

The figure 6 shows the Tensile Strength, Shear Strength, Dynamic Mechanical analysis (Bending Mode) Samples.

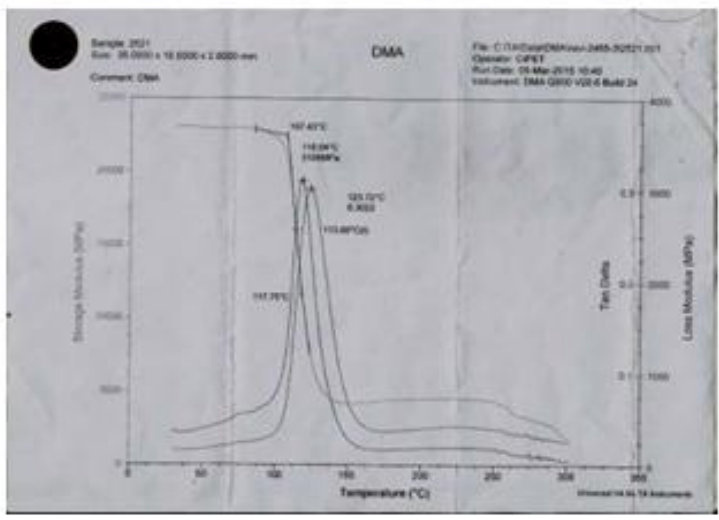

Fig. 7.Graph DMA Thermograph.

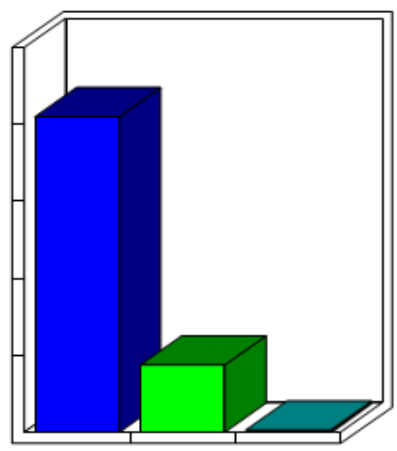

Fig. 8.Graph C.E \%.

From the above figure 7 shows the DMA Thermograph, the storage modulus is to compute the elastic response of the composite, is $19500(\mathrm{MPa})$ and the loss modulus $(\mathrm{MPa})$ is to calculate the viscous response of a material, it is $3106 \mathrm{MPa}$ at the temperature of $118.040 \mathrm{C}$. DMA helps to understand the bonding of the composites. The tensile strength and Shear Strength results shown in table 3. The Carbon Epoxy Composites rings can be used in illizarov fixator ring.

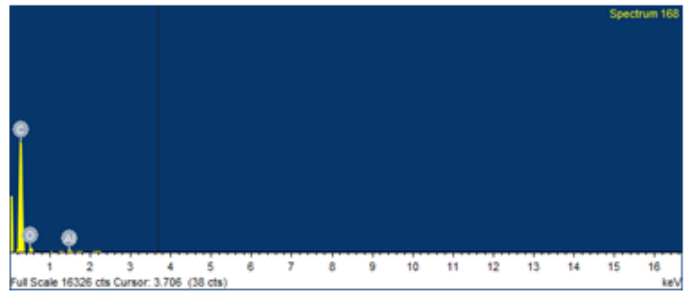

Fig. 9. EDAX, Carbon Epoxy Composite Material .

The figure 8 shows the Scanning Electron Microscope image of the fibres have delaminated. The figure 9 shows the percentage of carbon present in the composites. The EDAX results confirms the presence of carbon quantitatively.

\section{SIFC of Composite Fixator Plate}

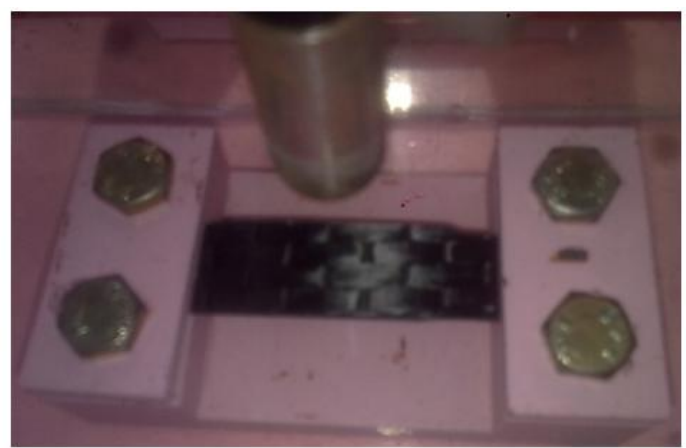

Fig. 10. Surface Impact Fatigue corrosion.

\section{Test on Composite plate}

The above figure 10 shows Fatigue corrosion test on composite plate. The plate fails for less number of cycles.

Delamination of the composite plate occurs due to the combined action of Impact and Fatigue. The SEM image of the Impact fatigue corrosion test 
confirms the delamination[12].

\section{E. Carbon Epoxy Composite Illizarov ring}

Carbon Epoxy specimen is prepared as per the standard procedure and test[13]. The figure 11 shows Carbon Epoxy Composite Illizarov Ring used in the Illizarov fixator. The ring is cut with the help of water jet machining.

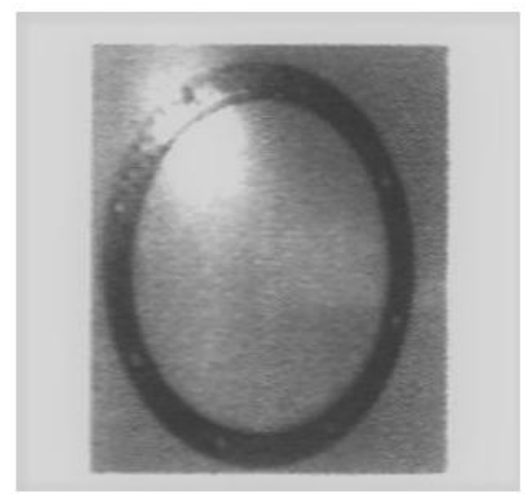

Fig. 11. Composite Illizarov ring .

\section{F. Tensile test on carbon Epoxy Sample}

Dimensions of the tensile test sample

Length: $65 \mathrm{~mm}$

Width : $14 \mathrm{~mm}$

Thickness: $2.36 \mathrm{~mm}$

Table- I: Temperature and impact energy values for carbon/ epoxy composite.

\begin{tabular}{|l|l|l|l|l|}
\hline \multicolumn{5}{|c|}{ Temperature } \\
\hline $\begin{array}{l}\text { Impact } \\
\text { Energy ( J) }\end{array}$ & 10 & 20 & 30 & 40 \\
\cline { 2 - 5 } & 1. & 1.8 & 2.8 & 3.3 \\
\hline
\end{tabular}

\section{G. Impact Test on Carbon Epoxy Sample}

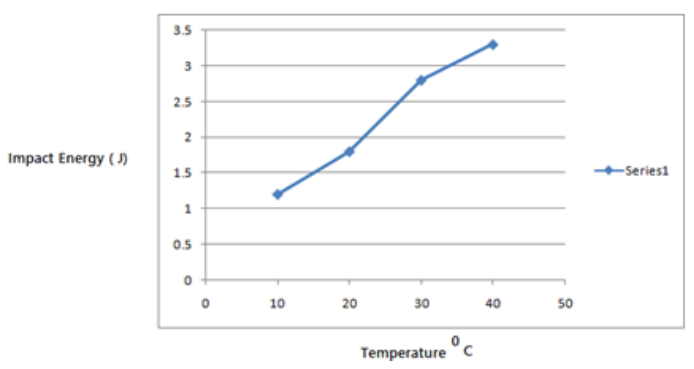

Fig. 12. Graph of Impact energy in carbon epoxy composite.

The Table I and figure 12 shows graph of the Impact energy of carbon epoxy composite for different temperatures.

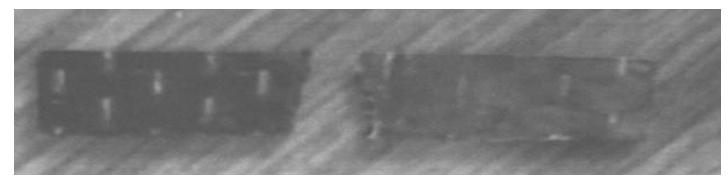

Fig. 13. Composite Illizarov Plate .

Figure 13 Impact test Specimen of carbon epoxy composite. The impact strength of the plate is 4.6 joules. The graph between impact energy and temperature is plotted and the required graph is drawn in figure 12. The sample is shown in fig. 14.

Dimensions of the tensile test sample

Length : $250 \mathrm{~mm}$

Width : $25.20 \mathrm{~mm}$

Thickness: $2.60 \mathrm{~mm}$

For a load of $1.50 \mathrm{KN}$ there is a maximum deflection of $6.1 \mathrm{~mm}$ after which the test sample break into two pieces.

\section{H. Impact of carbon epoxy composite}

In various application of biomedical high impact load /strain rate is estimated. Therefore the sustainability of these applications is verified by the parameter and properties of energy absorbing. The combination of such efficient and safe design offers better tensile and impact properties which is consider to be important. Impact properties determines toughness of material through computing the specimen energy .

\section{Failure modes}

Failure is due to the imperfection in the fibers interface and flaws in matrix. After initiation of the failure, a simple model can be used to describe the fracture process during the propagation of a crack.

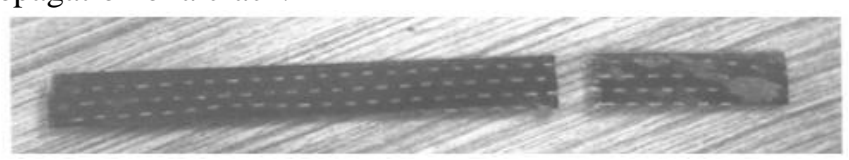

Fig. 14. Tensile Test on carbon epoxy composite .

The table: 2 shows tensile test and carbon epoxy composites and the figure 14 shows the tensile test specimen of carbon epoxy composites.

Table- II: Composite Plate Load deflection readings .

\begin{tabular}{|c|c|c|c|c|c|c|}
\hline $\begin{array}{c}\text { Load ( KN } \\
)\end{array}$ & 1.00 & 1.10 & 1.20 & 1.30 & 1.40 & 1.50 \\
\hline $\begin{array}{c}\text { Deflection } \\
(\mathrm{mm})\end{array}$ & 1.5 & 2.3 & 3.5 & 4.7 & 5.2 & 6.1 \\
\hline
\end{tabular}

Table- III: Composite Plate Dynamic Mechanical Analysis

\begin{tabular}{|l|l|l|l|l|}
\hline S.No & Property & $\begin{array}{l}\text { Standar } \\
\text { d }\end{array}$ & $\begin{array}{l}\text { Results } \\
\text { Obtaine } \\
\text { d }\end{array}$ & Test Duration \\
& & MPa & \\
\hline 1. & Tensile & ASTM & 614.0 & 264 hours \\
& Strength & D3039 & & \\
\hline 2. & Shear & ASTM D & 1445.4 & 264 hours \\
& Strength & 732 & & \\
\hline
\end{tabular}




\begin{tabular}{|l|l|l|l|l|}
\hline 3 & $\begin{array}{l}\text { Dynamic } \\
\text { Mechanic } \\
\text { al analysis } \\
\text { (Bending } \\
\text { Mode ) }\end{array}$ & & $\begin{array}{l}\text { Thermogr } \\
\text { aph }\end{array}$ & 264 hours \\
\hline
\end{tabular}

\section{CONCLUSION}

It is concluded that the experiments were carried out in carbon epoxy and biometals shows that the metals are more stronger than the carbon epoxy. The composite fracture plate is light in weight than the metal plate fixator. Delamination occurs in composite plate fixators. Biometal fixators corrosion is very less. It is further concluded where ever high strength is required metal fixators are used. When light weight is applied composite fixators are used.

\section{REFERENCES}

1. M T. Matsumura ,Y. Inoue,T. Takagi," Impact Fatigue Fracture of Axle-steel and Tire-steel", Quarterly Reports of the Railway Technical Researche Institute,Vol.24,No.2 1983.

2. M. T. Frey,I. Y. Tsai,T. P. Russell ,S. K. Hanks,Y. L. Wang," Cellular responses to substrate topography: role of myosin II and focal adhesion kinase", Biophysical journal,Vol.90,No.10,May.2006,pp.3774-82.

3. F. Variola, F. Vetrone ,L. Richert ,P. Jedrzejowski,J. H. Yi ,S. Zalzal ,S. Clair , A. Sarkissian , D. F. Perepichka, J. D. Wuest ,F. Rosei,” Improving biocompatibility of implantable metals by nanoscale modification of surfaces: an overview of strategies, fabrication methods, and challenges", small,Vol.5,No.9,May.2009,pp.996-1006.

4. M. T. Mathew, T. Uth , N. J. Hallab, R. Pourzal, A. Fischer, M. A. Wimmer," Construction of a tribocorrosion test apparatus for the hip joint: validation, test methodology and analysis", Wear,Jul. 2011,Vol.271,No.9-10,pp.2651-9.

5. S. Y. Yarema ,E. L. Kharish ," Crack nucleation and growth periods in 30CrMnSiNiA steel under repeated-impact tensile loads", Soviet materials science: a transl. of Fiziko-khimicheskaya mekhanika materialov/Academy of Sciences of the Ukrainian SSR,Vol.5,No.5,Sep. 1972 ,pp.432-4.

6. U. K. Mudali, T. M Sridhar ,B. Rai,"Corrosion of Bioimplants, sadhana”, Vol.28,No.324,2003,pp.601-37.

7. G. Ryan,A. Pandit,D. P. Apatsidis," Fabrication methods of porous metals for use in orthopaedic applications", Biomaterials,Vol.27,No.13,May. 2006,pp.2651-70.

8. A Sargeant ,T. Goswami "' Hip implants: paper V. Physiological effects", Materials \& design,Vol.27,No.4,Jan. 2006,pp.287-307.

9. K. S. Kumar, P. Vijian ,J. S. Solomon ,L. J. Berchmans, " Corrosion Studies on Stainless Steel 304 in Brackish Environment", Int. J. Emerg. Tech. Adv. Eng,Vol.2,Nov.2012,pp.178-82.

10. G. N. Rao, M. H. Rao, B. A. Rao ,P. K. Sagar ," Electrochemical characterization of biomedical titanium alloy Ti-35Nb-7Zr-5Ta" International Journal of Advanced Engineering TechnologyVol.3,No.1, 2012,pp.217-22.

11. M. Matsuura ,S. Lounici ,N. Inoue ,S. Walulik ,E. Y. Chao,” Assessment of external fixator reusability using load-and cycle-dependent tests", Clinical Orthopaedics and Related Research,Vol.406,No.1,Jan.2003,pp.275-81.

12. W. Li,X. H. Tu ,J. Y. Su, Q. D. Zhou ," Microstructure, impact fatigue resistance and impact wear resistance of wear resistant low Cr-Si cast iron," $\begin{array}{llll}\text { JOURNAL OF IRON AND } & \text { STEEL }\end{array}$ RESEARCH-INTERNATIONAL,Vol.8,No.2,Nov. 2001,pp.47-50.

13. P.Sathish kumar, R. Ramadoss,"INVESTIGATION OF MECHANICAL PROPERTIES AND TRIBOLOGICAL BEHAVIOUR OF BAGASSE FIBER REINFORCED POLYMER COMPOSITE", International Journal of MC Square Scientific Research, Vol.9, No.2, 2017,pp.86-96.

\section{AUTHORS PROFILE}

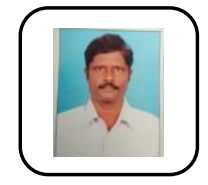

Dr. D. Bubesh Kumar, is working as an Associate Professor in the Department of Mechanical Engineering. Aarupadaiveedu Institute of Technology , Vinayaka
Missions University. He has published more than 15 research papers, He has written a book in the area of

Fatigue corrosion of Biomaterials He has completed his

$\mathrm{Ph} . \mathrm{D}$ in the area of Biomedical Implants and fixators

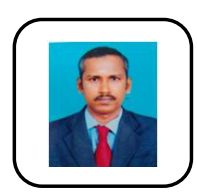

P.Kumaran is working as an Assistant Professor in the Department of Mechanical Engineering. Aarupadaiveedu Institute of Technology, Vinayaka Missions University. He has published more than 5 research.

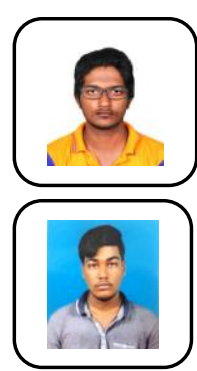

David Barnabas, is a UG Research Scholar in the Department of Mechanical Engineering, Aarupadai Veedu Institute of Technology. Vinayaka Missions University

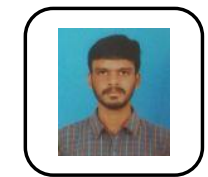

Akash J, is a UG Research Scholar in the Department of Mechanical Engineering, Aarupadai Veedu Institute of Technology, Vinayaka Missions University.

Jagadeeswaran S, is a UG Research Scholar in the Department of Mechanical Engineering, Aarupadai Veedu Institute of Technology, Vinayaka Missions University. 